\title{
Bitcoin: materialidades, liberdades e interações de uma moeda-rede
}

\section{Bitcoin: materialities, freedoms and interactions of a network currency}

\author{
Luiz Arthur Silva de Faria \\ Programa de Pós-Graduação em História das Ciências e das Técnicas e \\ Epistemologia (HCTE), Universidade Federal do Rio de Janeiro (UFRJ) \\ luizart@gmail.com \\ https://orcid.org/0000-0001-6456-8015
}

\begin{abstract}
Resumo. A Bitcoin suscita discursos de liberdade em relação a governos, bancos centrais e grandes bancos, de um lado, e críticas que aproximam a proposta de moeda do mundo da especulação financeira, de outro. Analisaremos brevemente neste trabalho alguns aspectos da recente história de tensão entre esses dois olhares sobre esta moeda suportada por diferentes elementos de tecnologias da informação, como softwares, hardwares e protocolos. Considerando que há opções inscritas nos códigos, como a quantidade de moeda disponível e uma versão particular de descentralização centrada no indivíduo, as reflexões do trabalho apontam para o reconhecimento de que a Bitcoin não está separada tanto do que poderíamos chamar de micropolítica daqueles que projetaram seus algoritmos e códigos quanto da macropolítica da governança da Internet.
\end{abstract}

Palavras-chave: Moedas digitais. Descentralização. Política.

\begin{abstract}
Bitcoin fosters freedom speeches in relation to governments, central banks and large private banks, on the one hand, and criticisms that bring the world's currency proposal closer to financial speculation, on the other. This paper briefly analyzes some aspects of the recent history of tensions between these two views on this currency which is supported by different elements of information technologies, such as software, hardware and protocols. Considering that there are options inscribed in the Bitcoin codes, such as the amount of currency available and a particular version of decentralization centered on the individual, the reflections of the work point to the recognition that Bitcoin is not so separate from what we could call the micropolitics of those who designed their algorithms and codes and the macro-politics of Internet governance.
\end{abstract}

Keywords: Digital currencies. Descentralization. Politics. 
Recebido: 01/10/2017. Aceito: 27/10/2017. Publicado: 06/11/2017

\section{Introdução}

Cena 1". Marcos, tido como "um hacker meio anarquista" por seus colegas de graduação em computação, finalmente chega ao Fórum Internacional de Software Livre (FISL). Ele tinha estudado bem a grade do evento, e estava interessado em temas sobre moedas alternativas. Naquela tarde, caminhava pra mais uma palestra sobre Bitcoin. Entra no auditório, senta. De manhã já tinha ido a outra apresentação que tratava da moeda digital, mas achou "meio teoria da conspiração, falando de guerra cibernética, de bancos centrais e tal", como comentou com o rapaz ao seu lado. Auditório cheio e apertado, começa a palestra: "Gente, vocês não acreditam no sonho que tive!! Eu imaginava em fazer nossas próprias moedas, sem depender desses governos! Podíamos estabelecer nós mesmos uma regra pra criação dessas moedas. As transações seriam anônimas, ninguém tem que ficar sabendo o que eu comprei ou vendi. Talvez, as pessoas pudessem ajudar a validar cada transferência da moeda, mas de uma forma que elas não poderiam saber quem faz parte da transação. E quem fizesse isso ganharia algumas moedas como prêmio. Com as possibilidades da Internet, o registro de todas as transações que rolaram na rede ficaria aberto, apenas sem identificar exatamente a pessoa. E sem ninguém controlando, no esquema do compartilhamento de músicas, ponto a ponto. Isso era no sonho... Mas... não é sonho, pessoal! Como alguns aqui devem saber, um tal de Satoshi esteve trabalhando em um novo sistema de dinheiro eletrônico que é completamente ponto a ponto, sem precisar de um servidor central. Ele resolveu o problema da segurança com esse tipo de rede, não tem nenhuma instituição centralizada pra emissão de moedas e os participantes podem ser anônimos. O cara mandou o link pra um paper e tudo. Acho que tô sonhando ainda...". Nesse momento, Marcos não pôde deixar de perceber um sotaque carioca (como o dele) vindo da conversa à sua direita: "meu irmão, com isso aí, em 20 anos não vai haver mais fronteiras entre os países. Os Estados se mantém por causa das moedas... Acabou isso!! Essa é mundial, não tem como os governos controlarem". A conversa quase faz Marcos perder a intervenção de alguém insatisfeito com o discurso do palestrante: "Deixa eu falar, você não pode me impedir! Eu participei dessa comunidade da Bitcoin no Brasil desde o início. Era uma alternativa lá atrás, pelo menos eu achava. Mas agora só serve pra especular e ganhar dinheiro.

$1 \mathrm{O}$ recurso da utilização de cenas busca reunir elementos de destaque do artigo. Esta cena foi baseada em ZAIDAN (2014) e no próprio e-mail de Satoshi Nakamoto, disponível em <http://libertyblitzkrieg.com/2013/10/31/five-years-ago-today-bitcoin-was-born-read-satoshis-originalwhite-paper/>. Acesso em: 10 jun. 2019. Contém elementos de minhas vivências nos Fóruns Internacionais de Software Livre (FISLs 15 e 16, em 2014 e 2015), Latinoware (2015), e no III Fórum de Cidadania Financeira do BACEN. Para conferir outros exemplos do uso de cenas, ver Latour (2000), ou Faria (2018). 
Você tem que falar disso também. Não pode deixar de falar!" Silencio no auditório, climão... Agora foi a vez de Marcos prestar atenção num rapaz sentado à sua esquerda, que não se conteve. Virou-se pra Marcos e soltou: "Véi, cada vez eu me convenço mais que essa Bitcoin não resolve nada... Depois vê se passa na sala 110. Vou apresentar daqui a pouco uma experiência com outra história de moeda digital, na economia solidária". Marcos não conhecia o rapaz, apenas percebeu que o sotaque vinha de algum ponto do nordeste brasileiro. Bateu nos ombros de Marcos, levantou e saiu da sala.

A cena 1 é fictícia, mas inspirada na realidade. $O$ discurso de liberdade e de alternativa em relação a governos, bancos centrais e grandes bancos, controladores das moedas que circulam na maior parte dos países, de um lado, e as críticas que aproximam a Bitcoin do mundo da especulação financeira, de outro, foram observadas por este pesquisador na circulação da "primeira moeda digital descentralizada", como Kemel Zaidan (2014) caracteriza a Bitcoin, em fóruns sobre software livre e inclusão financeira. Analiso brevemente neste trabalho alguns aspectos da tensão entre esses dois olhares sobre esta (proposta de) moeda suportada por diferentes elementos de tecnologias da informação, como softwares, hardwares e protocolos.

Além das vivências nesses espaços, o presente artigo resulta da análise de entrevistas semiestruturadas e de literaturas sobre o tema. Trata-se de parte da investigação sobre as opções de digitalização de "moedas sociais" do Brasil (FARIA, 2018), tema que conectase com outras modalidades de moedas, como a Bitcoin. O artigo resgata assim, brevemente, um recorte da história da construção da Bitcoin no Brasil, em especial colocada em circulação por atores que circularam nos espaços mencionados. Propõe um diálogo amplo e interdisciplinar, partindo da abordagem metodológica da Teoria AtorRede, dentro do campo dos Estudos em Ciência, Tecnologia e Sociedade, que entre outras premissas prega uma postura de "mochila leve"2 (FARIA 2018) do pesquisador, bem como a indissociabilidade entre aspectos técnicos e sociais de artefatos.

\section{A moeda-rede Bitcoin}

Em 31/10/2008, Satoshi Nakamoto envia e-mail com white paper para uma lista de criptografia cypherpunk, lançando as bases e as primeiras implementações da Bitcoin (ZAIDAN, 2014). Suas regras são inscritas nas linhas de código dos programas que dão vida à proposta de moeda, e que funcionam em celulares, tablets, laptops etc. Segundo elas, qualquer transação realizada em Bitcoin fica registrada em uma espécie de livro caixa (public ledger) que contém todas as transações já realizadas na rede, uma de suas

\footnotetext{
2 “O equipamento necessário para viajar pela ciência e pela tecnologia é, ao mesmo tempo, leve evariado. Variado porque é preciso misturar pontes de hidrogênio com prazos finais, exame dacapacidade alheia com dinheiro, correção de sistemas de computadores com estilo burocrático;mas o equipamento também é leve porque convém deixar de lado todos os preconceitos sobreas distinções entre o contexto em que o saber está inserido e o próprio saber" (LATOUR, c1998,p. 20).
} 
grandes novidades. Periodicamente, (a cada dez minutos, segundo Zaidan (2014)), a rede reúne as páginas do livro, ou melhor, os blocos da cadeia, que registra sequencialmente as transações e as torna públicas - contudo sem abrir mão do anonimato das pessoas envolvidas. Essa publicidade das transações é um forte aliado à segurança da rede (CRIPPA, 2014) $)^{3}$.

Também incorporado nos códigos, o anonimato é garantido pela criptografia e por um mecanismo de chaves assimétricas. Em resumo, cada usuário na rede corresponde a uma chave pública (conhecida pelos outros membros da rede, ou seja, computadores) e a uma chave privada, a que somente o próprio usuário tem acesso. Outra característica fundamental da moeda-rede Bitcoin é que ela utiliza uma rede de computadores cuja arquitetura pode ser caracterizada como ponto-a-ponto (peer-to-peer, ou P2P). Significa dizer que a rede não possui um servidor central, ou seja, a validação de qualquer transação em Bitcoin é feita numa rede distribuída.

Essa arquitetura é uma pista para as formas de geração e circulação da nossa moeda-rede: não há uma entidade central emissora de Bitcoin. As moedas são geradas e atribuídas, como um prêmio, aos usuários que colocam à disposição da rede um esforço computacional para validar as transações realizadas em Bitcoins (ZAIDAN, 2014). Esse processo é chamado de mineração de Bitcoins: os usuários que validam transações recebem moedas, segundo Wladimir Crippa (2014), a uma taxa na rede aproximada de 25 Bitcoins a cada 10 minutos.

Mineração, peer-to-peer e criptografia poderiam ser nomeadas, apressadamente, características técnicas da Bitcoin. Porém, mais cuidadosamente, é possível perceber que tais atores não-humanos embutem escolhas e propagam efeitos que poderíamos chamar sociais ou políticos, o que torna essa fronteira um tanto borrada. Considerando as discussões de diferentes fóruns e pesquisadores sobre o caráter monetário (ou não) da Bitcoin (SCOTT, 2014) (DODD, 2017), cabe aqui dialogar com o campo da antropologia da economia: reflexões como as de George Dalton (1967), ao analisar diferenças entre os usos e significados do dinheiro em diferentes sociedades, nos interessam aqui. O autor coloca que

a questão não é se - como convencionalmente colocado - (...) gados, bodes [etc.] (...) são 'realmente' 'dinheiro'?" É, ao invés disso, como as similaridades e diferenças entre tais itens [das sociedades primitivas] e os dólares [das atuais] se relacionam com similaridades e diferenças na estrutura sócio-econômica?

\footnotetext{
${ }^{3}$ A Bitcoin utiliza a tecnologia blockchain (cadeia de blocos) como base. "[...] [U]m bloco é um arquivo que contém um cabeçalho que o identifica [... seguida] do registrodas transações mais recentes efetuadas com as bitcoins e que ainda não foram registradas emoutros blocos. É mais ou menos análogo a uma página individual de um grande livro registratransaçõesefetuadasemumabolsadevalores."Fonte: $<$ http://www.techtudo.com.br/artigos/noticia/20 14/01/bitcoin-os-blocos-e-sua-cadeia.html>.Acesso em: 03 set. 2019. O detalhamento da blockchain não é objeto deste artigo. Mais em, por exemplo, Diniz, Cernev, Daneluzzi e Rodrigues (2018) e em Kewell, Adams e Parry (2017).
} 
Dalton (1967) argumenta que, ao examinar atentamente as moedas, é possível (e necessário) ver a estrutura socioeconômica. $\mathrm{O}$ artefato em questão, a moeda, seria indissociável dessa estrutura. Dialogando com essa abordagem e com Bruno Latour (2000), podemos propor que a observação cuidadosa dos artefatos tecnológicos que circulam na rede da Bitcoin - aliados não-humanos da rede -, nos leva a noções, argumentos e teorias associados à proposição da moeda-rede Bitcoin. É o que veremos adiante, ao mesmo tempo que acompanhamos os construtores brasileiros da Bitcoin na busca por mais aliados e pela confiança do público.

\section{Imbricações com as macropolíticas da Internet}

Observando as apresentações sobre Bitcoin e criptomoedas no FISL e LATINOWARE, não foi difícil identificar um argumento apresentado como favorável para o uso da moeda alternativa: sua pretensa independência em relação a governos e sistemas políticos, por um lado, e a bancos centrais e ao sistema bancário em geral por outro. $\mathrm{O}$ que regulamentaria a Bitcoin seria o protocolo, e, portanto, a rede não dependeria de bancos ou governos pra existir - uma vantagem, na visão de Zaidan (2014). Uma das facetas dessa independência ganha a forma da defesa do anonimato, e seu tom parece guardar relação com aquele usado por Eric Hughes, programador que escreveu o "Manifesto Cypherpunk" em 1998 e que defendia o uso de criptografia para proteger a privacidade na era da informação. Ele argumenta que

\footnotetext{
[s]e eu compro uma revista de uma loja e dou dinheiro para o caixa, não há necessidade de ele saber quem eu sou. (...). Se eu peço ao meu provedor de correio eletrônico para mandar e receber mensagens, meu provedor não precisa saber com quem eu estou falando ou o que outros estão me dizendo; meu provedor só precisa saber como levar a mensagem até lá e quanto eu devo.
}

A preocupação com o anonimato e a privacidade é situada por Pedro Rezende (2014) na história da digitalização das moedas, para o autor um fenômeno não inaugurado com a Bitcoin. Os bancos, provendo operações eletrônicas já há muito teriam atentado para este processo, além de beneficiarem-se de uma importante diferença que a materialidade das operações eletrônicas traz, quando comparada por exemplo com o papel-moeda: a rastreabilidade. Na visão de Rezende (2014), tal característica permite que os bancos ofereçam mais versatilidade em troca da privacidade dos usuários (essa, compartilhada com as instituições financeiras). Uma saída possível (para a contestada centralidade dos bancos e o uso de dados privados) estaria na tecnologia, que permitiu sair de uma ideia de validação centralizada das transações para um arranjo descentralizado, como vimos por conta das tecnologias P2P. Nesse novo arranjo, tendo um software como um dos protagonistas, o poder teria sido deslocado, já que nas "moedas livres" (REZENDE, 2014):

Quem controla a emissão é um protocolo distribuído acordado por quem implementou o artigo original de Satoshi Nakamoto. Quem emite moeda é o protocolo (...). Quem pode entrar? Quem quiser. Quem pode rodar o código? 
Quem quiser. Quem pode examinar o código? Quem quiser. (REZENDE, 2014)

Anonimato, certa aversão a governos e bancos, elogio aos protocolos e tecnologias são ideias obviamente não exclusivas dos (mas presentes nos) circuitos da Bitcoin. Crippa (2014) posiciona a Bitcoin nos contextos mais amplos da revolução digital e da democracia direta. Entre os indícios de uma visão libertária, bastante comum nas discussões sobre um dos ícones da revolução digital, a Internet, está a "Declaração de Independência do Ciberespaço". Ela proclama:

[ó], Governos do Mundo Industrial, esgotados gigantes de carne e aço, eu venho do ciberespaço, a nova morada da mente. Em nome do futuro, eu peço a vocês do passado que nos deixem em paz. Vocês não são bem-vindos entre nós. Vocês não têm soberania onde nos reunimos. [...] Declaro que o espaço social global que estamos construindo é naturalmente independente das tiranias que vocês querem nos impor. (BARLOW, 1996, apud CARVALHO et al., 2005, p. 58)

Parece pertinente assim situar os valores libertários que atravessam a rede da Bitcoin como estando imbricados com os discursos e visões de mundo que circulam entre militantes da Internet, do protocolo P2P e do software livre, como transparece na fala de Crippa (2014): para ele, o "Mp3 é uma porta de entrada para 'drogas mais pesadas' como Bitcoin". Contudo, vale aqui pontuar que, como discutimos em outro momento, ainda que valorizando as diversas lutas políticas por práticas democráticas relacionadas à Internet, é preciso relativizar a visão que advoga uma independência natural do ciberespaço e uma descentralização do poder na Internet, por exemplo, lembrando que a redistribuição de recursos e de poder do "modelo descentralizado de comunicação [da Internet], baseado no protocolo TCP/IP” (CARVALHO et al., 2005, p. 61) não está apartada de seu sistema de endereçamento, que define a própria existência de um computador na Internet e é centralizado (CARVALHO et al., 2005) (FARIA, 2010). Desta forma, cabe lembrar que a Internet não existe totalmente apartada da política e dos Estados.

\section{Indissociabilidades: micropolítica dos programadores e surpresas materiais}

Importa também examinar aqui o que se pode chamar "elogio aos protocolos e tecnologias" que circulam na moeda-rede Bitcoin, como uma possível alternativa às esferas políticas. Como já pontuado, os Estudos CTS demonstram a não neutralidade da ciência e das tecnologias: "todo desenvolvimento tecnológico implica escolhas, e os artefatos não nascem apartados das associações engendradas com o objetivo de produzilos" (FARIA, 2010). No caso da Internet, 


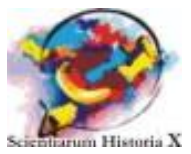

em oposição à ideia de que o ciberespaço é um território sem leis, livre inclusive da influência dos governos - importa chamar a atenção para os códigos que permeiam a Internet: eles delimitam poderes dos usuários (CARVALHO et al., 2005), configurando as regras e empoderando mais - ou menos - aqueles que ali agem. Pode-se dizer assim que os códigos reconfiguram agenciamentos. Nas palavras de Lawrence Lessig (1999, p. 5), “o que faz o ciberespaço tão diferente é que ele é constituído por essas leis da natureza que escrevemos", os códigos dos softwares que conformam a grande rede. (FARIA, 2010)

Há política na tecnologia: há opções inscritas nos códigos, adotadas pelos construtores dos algoritmos e códigos, como a opção dos construtores da Bitcoin por delimitar a quantidade de moeda em um teto; há efeitos no uso da Bitcoin, efeitos esses relacionados com as opções e materialidades embutidas na moeda: por ser intensiva em tecnologias da informação, pode-se dizer que o uso da moeda inclui aqueles que dominam razoavelmente suas linguagens e exclui, ao menos temporariamente, os que as ignoram. De forma bastante crítica, Scott (2014) coloca:

[s]e você está na posição de sonhar com uma saída tecnológica, você provavelmente não está em uma posição de sair da sociedade mainstream. Você é sociedade mainstream.

Ainda no campo das políticas embutidas na Bitcoin, encontramos uma versão particular de descentralização. Nela, a alternativa à concentração promovida por bancos centrais e grandes bancos é substituída, em tese, pela noção de indivíduo. Uma opção que desconsidera, por exemplo, o tema da proximidade, tão caro às metodologias de moedas alternativas no campo da economia solidária (FARIA, 21018), como nos casos dos Bancos Comunitários de Desenvolvimento (BCDs) e das Produtoras Culturais Colaborativas, passa ao largo dos militantes brasileiros da Bitcoin. Um indicador percebido no FISL: ao ser apresentado à metodologia dos $\mathrm{BCDs}$, a primeira reação de Wladimir Crippa (2015) (um de seus porta-vozes em encontros como o FISL) foi compará-la às Dotz. A comparação faz sentido no escopo desta proposta de moeda alternativa, onde uma descentralização extrema das instâncias validadoras das transações financeiras é um valor que circula tanto nos discursos quanto em seus artefatos. A própria existência de um banco comunitário como uma instância de relativo poder local soa estranha à "cosmologia" da Bitcoin. Contudo, Joaquim Melo, pioneiro na metodologia dos BCDs, aponta grandes diferenças das Dotz em relação aos BCDs: não possui lastro em Reais, seu espaço de circulação se estende por todo o território nacional, e não se sabe "quem é o dono, quem administra, a quem ela beneficia" (MELO NETO SEGUNDO, 2012).

Cabe ressaltar adicionalmente que os valores que influenciam e são embutidos em um artefato tecnológico, como a Bitcoin, não são propagados necessariamente da mesma maneira. Se o presente artigo se afasta de uma noção de determinismo tecnológico, também não se aproximamos de um determinismo social: as materialidades promovem surpresas. Em nosso caso, chama a atenção que o processo de minerar Bitcoins foi 
progressivamente tornando-se uma tarefa árdua, para especialistas. Um usuário comum, utilizando um desktop, já não há algum tempo não consegue mais atualmente obter muitas Bitcoins a partir da mineração (ZAIDAN, 2014). Surgiram inclusive pools que "movimentam a economia Bitcoin", além das "benditas máquinas projetadas só pra minerar Bitcoin" (CRIPPA, 2014). Esta surpresa material oferece uma vantagem para aqueles que têm condição de investir Reais em máquinas poderosas, que produzam mais Bitcoins: assim, a suposta intenção descentralizadora ganha contornos de promotora de novas concentrações.

\section{Algumas conclusões}

Este breve artigo buscou, especialmente a partir dos atores que circularam com o temas da Bitcoin em fóruns brasileiros, fazer emergir imbricações entre aspectos "ténicos" $\mathrm{e}$ "sociais" desta, aqui chamada, moeda-rede. Demonstramos que não se deve imaginar que, adotando uma "moeda livre" cujo funcionamento não seja supostamente determinado diretamente por governos e bancos, estaremos livres dessas institucionalidades e de suas políticas constituintes. Apesar de concordar com Zaidan (2014), quando argumenta que "não é fácil acabar com a Bitcoin (...) por ser uma rede [distribuída] P2P", e de ser fundamental lembrar que os códigos-fonte são muitas vezes licenciados como softwares livres (ou seja, sempre é possível modificar o código-fonte e propor construir outra rede, com outra moeda), melhor imaginar que as relações e os poderes podem ser reconfigurados sim pela Bitcoin, em outros termos; porém, termos esses que não serão isentos de opções, restrições, facilidades, de políticas. "Somente se escapa para um conjunto diferente de regras, não controlada por políticos, mas nas mãos de programadores e daqueles que controlam o poder computacional", como coloca (SCOTT, 2014).

As moedas das sociedades modernas estão em geral conectadas a autoridades centralizadas, bancos centrais, e intimamente ligadas aos governos. Se isso é sim verdade, é importante também reconhecer que a Bitcoin não está separada, por um lado, do que poderíamos chamar de micropolítica daqueles que projetaram seus algoritmos e códigos, nem mesmo, por outro, da macropolítica da governança da Internet.

\section{Referências}

CARVALHO, M. S., CUKIERMAN, H. L., \& MARQUES, I. D. C. 2005. A governança da Internet: o controle do namespace no ciberespaço. In: AFONSO, Carlos A. (Org.). Governança da Internet: contexto, impasses e caminhos. São Paulo: Peirópolis, p. 5877. 
CRIPPA, W., 2014. Bitcoin: a Revolução Digital chegou à economia. Palestra apresentada ao Fórum Internacional de Software Livre 2014. Porto Alegre, em 8 mai. 2014.

, Wladimir, 2015. [Sobre o Bitcoin]. Porto Alegre. Entrevista concedida a Luiz Arthur Silva de Faria em 08 de junho de 2015.

DALTON, G., 1967. Primitive Money. In Tribal and Peasant Economies. Readings in Economic Anthropology, edited by George Dalton, 254-81. New York: The Natural History Press.

DINIZ, E. H., CERNEV, A. K., DANELUZZI, F. L., \& RODRIGUES, D. (2018b). Social cryptocurrencies: social finance organizations at the new era of digital community

DINIZ, E. H., SIQUEIRA, E. S., \& VAN HECK, E. (2019). Taxonomy of digital community currency platforms. Information Technology for Development, 25(1), 6991.

DODD, N.. The social life of Bitcoin. Theory, Culture \& Society, London, v. 35, n. 3,p. 35-56, 2017. Disponível em: <http://eprints.lse.ac.uk/69229/>. Acesso em: 15 fev. 2017. KEWELL, B., ADAMS, R., PARRY, G. C. (2017). Blockchain for Good? Strategic Change. forthcoming. 10.1002/jsc.2143.

FARIA, L. A. S., 2010. Softwares livres, economia solidária e o fortalecimento de práticas democráticas: três casos brasileiros/Luiz Arthur Silva de Faria. - Rio de Janeiro: UFRJ/COPPE, 2010.

FARIA, L. A. S., Digitalizações de moedas sociais no Brasil e suas(Pré)Histórias: tensões e mediações com Estados, mercados e tecnologias. Tese (Doutorado em História das Ciências e das Técnicas e Epistemologia) - Programa em História das Ciências e das Técnicas e Epistemologia, Universidade Federal do Rio de Janeiro, Rio de Janeiro, 2018.

FARIA, L. A. S., PAVAN, H. 2019. An analysis of cryptocurrencies as a phenomenon of innovation: impact on monetary systems and possibilities of social appropriations. data. In: 5th Biennial RAMICS International Congress in Japan.

FARIA, L. A. S., SEVERO, G. S., CUKIERMAN H. L., DINIZ E. H. 2019. Mumbuca E-dinheiro and the challenges of community governance: the requirements, codes and data. In: 5th Biennial RAMICS International Congress in Japan. 
JATOBÁ, P. H., 2013. [Sobre a moeda Conchas, o Corais.org, a Produtora Cultural Colabor@tiva.PE, e a Rede de Produtoras Colaborativas segundo a visão de um dos desenvolvedores da metodologia das Produtoras Culturais Colaborativas]. Entrevista concedida via skype a Luiz Arthur Silva de Faria em 06 de setembro de 2013.

LATOUR, B., 2000 [1998]. Ciência em ação: como seguir cientistas e engenheiros sociedade afora. São Paulo, UNESP.

MELO NETO SEGUNDO, J. J., 2012. Uma segunda moeda agora pode? Disponível em <http://empreendedorsocial.blogfolha.uol.com.br/2012/07/11/uma-segunda-moedaagora-pode/> Acesso em 01 jun. 2013.

REZENDE, P. A. D., 2014. Possíveis futuros para o último bastião da liberdade digital: as Criptomoedas. Palestra apresentada ao Fórum Internacional de Software Livre 2014. Porto Alegre, em 8 mai. 2014.

SCOTT, B., 2014. Visions of a Techno-Leviathan: The Politics of the Bitcoin Blockchain. Disponível em < http://www.e-ir.info/2014/06/01/visions-of-a-technoleviathan-the-politics-of-the-bitcoin-blockchain/>Acesso em 01 jun. 2014.

ZAIDAN, K., 2014. Bitcoin: o futuro do dinheiro é open source (e livre). Palestra apresentada ao Fórum Internacional de Software Livre 2014. Porto Alegre, em 7 mai. 2014. 